\title{
FROZEN STORIES Capturing and Utilizing Frozen Stories for Teaching of Project Managers
}

\author{
Tanja Buttler, Stephan Lukosch, Alexander Verbraeck \\ Faculty of Technology Policy and Management \\ Delft University of Technology \\ P.O. box 5015, 2600 GA Delft, The Netherlands \\ t.buttler@tudelft.nl,s.g.lukosch@tudelft.nl,a.verbraeck@tudelft.nl
}

Keywords: narratives, storytelling, project management, knowledge management

\begin{abstract}
Learning from projects is one of the major challenges which appears to be critical to consistent success of project-based organizations. To learn from past projects for current problem situations, knowledge and experience often has to be shared across time or space. However, while it seems to be possible to capture explicit knowledge (e.g. about products and technical problems), softer types of knowledge (i.e. knowledge about the processes that a team had deployed to achieve their goals and why these processes seemed to have worked well or badly) are more difficult to retain. By observing how knowledge people like managers or engineers communicate, we have found that they tell stories. Stories are an ancient way to communicate experiences (i.e. direct observations of or participation in events as a basis of knowledge) and are used by todays engineers to convey the challenges and solutions they encountered. Based on these grounds we propose an approach to freeze stories of project managers by capturing (and processing) their stories and thereby opening up an opportunity for sharing these stories across space and time. First trials of this approach are promising: it was easy for project managers to share experiences resulting in rich accounts. In addition, we tested the acceptance and applicability of frozen stories with apprentice project managers. We found that it reminded them of their own experiences and of stories they have heard. Furthermore, it stimulated the exchange of experiences with peers.
\end{abstract}

\section{INTRODUCTION}

Within project based organizations there is some concern over retaining the knowledge and experiences gained in a project. Organizations fear to lose knowledge and expertise needed for their next projects resulting in reinventing the wheel and repeating mistakes. Knowledge people such as engineers or project managers use their minds; this means they own their means of production - when they leave, they take this means of production with them (Stauffer, 1999). The work of knowledge people is characterized by an emphasis on creativity, use of social and analytical skills as well as theoretical knowledge (Newell et al., 2002). Knowledge people apply their skills and experience to identify and solve problems (Newell et al., 2002) or to make decisions (e.g. Simon, 1977). With regard to activities like decision making, innovation or problem solving in projects their knowledge and experience is invaluable. They contribute to these activities based on their experience and vast knowledge base. We can learn from past experiences and apply them in the current situation. Sage and Armstrong (2000) argue for example that information about past decisions should inform present decisions. However, to apply knowledge of knowledge people from one project within new situations in another project, knowledge and experience often has to be shared across time or space.

This challenge has been tackled within the domain of knowledge management. Within this domain knowledge can be understood as something an individual has learned through personal experiences (Jashapara, 2004); it is shaped by the social reality of the individual (Spender, 1996; Spender, 1998) and partially tacit (Nonaka and Takeuchi, 1995). Knowledge management is about creating new knowledge, distributing existing knowledge and training (Jashapara, 2004; Newell et al., 2002); for some it means 
codifying information in databases and distributing it through the intranet (Hansen et al., 1999), for others it means searching for and working with experts (Hansen et al., 1999), and for some it involves mentoring and informal learning to develop expertise (Newell et al., 2002).

Capturing the knowledge of knowledge people working on a project and storing it in knowledge management systems is one of its core tasks. However, past efforts to capture and reuse knowledge through knowledge management systems are not as effective as expected (see e.g. McDermott, 1999; Grant and Qureshi, 2006). One reason for this lies in the tacit nature of part of this knowledge. It is therefore difficult to capture and transfer (Neuweg, 2006).

For organizations relying on the execution of projects this draws a bleak picture. Learning from projects and exchanging both explicit and tacit knowledge beyond the boundaries of a project has been identified as one of the critical success factors for projects (Cooke-Davies, 2002).

Stories are an ancient way to communicate experiences (Totzke, 2005). Stories can be understood as sequences of events, communicated verbally or in written form (Valle et al., 2003). Within this research we focus particularly on personal, verbally communicated stories. They are not just about an account of events, but also also convey cultural aspects (values, beliefs, norms and cultural practices), personal perceptions of circumstances or events, examples for good and bad practices, as well as speculations about what might have happened (Ochs and Capps, 2001; Bruner, 1991; Orr, 1996). In addition, stories are placed into context in order to improve understanding of the audience (Bruner, 1991). When these narratives are told in a conversation, the teller can adapt the narrative to the story listeners, e.g. by filling in the blanks as necessary (Bruner, 1991; Ochs and Capps, 2001) or by responding to posed questions and challenges (Ochs and Capps, 2001). Therefore, the story listeners act as interlocutors who shape the story together with the primary storyteller.

Under the designation of storytelling, stories are already purposefully used to elicit written accounts of experiences shared in a team (see e.g. Valle et al., 2003; Perret et al., 2004).

Based on these grounds we propose an approach to freeze stories of project managers, in order to share experiences across time and space. This approach consists of the two stages: capturing the experiences in interviews and processing these interviews in order to prepare the captured experiences for further use in educational settings. Through this approach, the storyteller cannot adapt the story to the audience anymore, or complement the story with experiences made in other projects. This is what we understand under "freezing" a story.

The capturing stage employs interviews (and therefore an interviewer to interact with) for eliciting the experiences. Another means to capture experiences might be through the aid of a specialized storytelling tool. This area of research is outside of the scope of this paper, see e.g. (Lukosch et al., 2008; Lukosch et al., in press) for some of our research in this area.

We evaluated the capturing stage by observing project managers who contributed their experiences and by analyzing the captured experiences. Early results show that through the capturing stage it is easy to share experiences resulting in rich accounts. In order to evaluate the processing stage, stories containing personal experiences and beliefs were selected and reconstructed. Finally, we tested the acceptance and applicability of frozen stories with apprentice project managers in a field experiment. We found that it stimulated them to share their own experiences as well as stories they have heard.

Within the remainder of this paper we explore the problem in more depth and present our approach in using stories to capture experiences, followed by a first exploratory study on how to capture stories in order to get a sufficient result for utilizing the stories in educational settings. Furthermore, we want to give a first impression on how these stories are received by apprentices in the area of project management.

\section{PROBLEM EXPLORATION}

Newell et al. (2006) have conducted interviews in several organizations on the effectiveness of their lessons learned efforts. Lessons learned are a common strategy to transfer knowledge between projects by capturing lessons and storing these in a database for others to use. The results of the interviews are telling. While it seems to be possible to capture knowledge about products, technical issues and achievements, softer types of knowledge (i.e. knowledge about the processes that a team had deployed to achieve their goals and why these processes seemed to have worked well or badly) are not retained. Sharing these softer types of knowledge still relied on people to communicate it personally. Considering the issue of experts leaving the organization this draws a bleak picture. The softer types of knowledge are essential for learning from past projects. However, sharing soft knowledge through personal communication is not an option - if people have left an organization for in- 
stance, they are not available for this kind of communication any more. Therefore, we have to capture softer types of knowledge, in order to share it across time and space.

Telling (and recording) stories might be a way to address this challenge: Stories are an ancient way to share experiences. Taking a mainly historical perspective, we can observe that in societies where the technologies of literacy (especially writing and print) are unfamiliar to most of the population, experiences and knowledge are shared in two ways: through (guided) imitation or through verbal communication - particularly through telling and retelling of stories (Totzke, 2005). In our own experience, expert project managers like to share the lessons they learned while dealing with problems in a project through stories (see also Section 4.1). Today, technical experts use stories to talk about their personal experiences, the challenges they encountered and the lessons they learned (Orr, 1996). The everyday practice in informal knowledge management further shows that softer kinds of knowledge are usually communicated in the form of stories (Brown and Duguid, 2000). This line of argumentation allows us to specify the first requirement: we have to elicit and record stories.

In addition, projects can be complex in themselves. Consider for example project managers doing projects all over the world. They have to deal with several cultural aspects: the culture at the target site, the culture of the people working on the project as well as the culture of the organization. New technologies or a big scope can add to the complexity of a project. Every experience gained in such a complex project is embedded in the context in which this experience was made. The necessity of providing context within or together with a story has also been acknowledged in literature, see e.g. (Perret et al., 2004; Valle et al., 2003). Therefore, captured experiences should refer to the context in which they occurred.

In capturing personal experiences we not only have to take into account the needs of the target group but also have to consider the needs of the experienced project managers. Here, previous attempts to gather similar experiences in written form have shown that project managers have little time to write up the lessons they learned (see e.g. Newell et al., 2006; Pelt, 2008). Therefore, we have to reduce the time a project manager spends on the process.

\subsection{USING STORIES FOR TRAINING OF ADULTS}

Stories are also used in educational settings. Within goal-based scenarios cover stories (often in the form of case studies) are used to frame authentic tasks designed to acquire skills (Schank et al., 1994). Here, stories are used to motivate student, not to share softer types of knowledge across time and space.

McDrury and Alterio (2003) use a storytelling approach (rooted in constructivism) to reflect on and learn from their own experiences. Their collaborative approach consists of five phases: story finding, story telling, story expanding, story processing and story reconstructing. Within this approach learners tell and listen to stories told by other learners in the same group. This approach only works when the learners have direct contact to each other.

There are several approaches using stories as teaching material. The case method is a teaching approach confronting students with real world problems. Argyris (1980) has identified key features of this approach: Real world problems are used. The involvement of the teacher is minimized, whereas the involvement of the learners is maximized with regard to stating their opinions, questioning the views of others, and making decisions. Here, stories are one means (among others) to provide information about the case.

Rickert and Schnalzer (2005) have presented an approach to use stories of master craftsmen in the field of metalworking to teach journeymen in that field. The stories are edited to fit into a didactic concept (e.g. problem based learning or case based learning) and presented in multimedia formats .

There has also been some research on how to use stories for training firefighters: Joung, Hesketh and Neal (2006) have compared stories of firefighters about mistakes, some stories describing the worst outcome, some stories containing near escapes. They have presented these stories to firefighters and assessed their ability to identify a range of problems and possible actions before acting. They found that stories describing the worst outcome had the greater impact. The goal is to build up expertise of the firefighters and improve their perception of a particular situation. While all these research approaches provide some insights into how to use the stories (also from a didactic point of view), they do not explore how to get and modify the stories. Furthermore, they do not focus on verbally told stories.

Gandelman and Santoro (2010a, 2010b) have proposed an approach to capture stories from real world situations in order to use them in training scenarios. 
Their focuses on reports gathered from several people involved in such a situation and editing the results to merge them into a story. However, so far there has been no research on actually using the resulting in a training scenario.

All in all, stories are used to provide insights into complex situations, help students to foster meaning and provide motivation. We are of the opinion that frozen stories are a vehicle to transfer experiences from experienced project managers to apprentice project managers.

\section{APPROACH}

Our storytelling approach aims at supporting the elicitation of personal experiences within a project. It consists of two stages: the elicitation of personal views and experiences through interviews and the processing of these interviews in order to prepare the elicited stories for further use in educational settings. Furthermore, we have to provide technology support for both stages.

\subsection{Elicitation of Personal Experiences}

In order to elicit personal experiences in an efficient manner for the experts involved, we use semistructured interviews conducted by experienced interviewers.

Capturing experiences through interviews has several advantages. First, interviews reduce the time a project manager has to spent on telling her stories. Second, having a person guiding through the storytelling provides additional motivation to actually telling the stories. Third, we can build on some of the characteristics of verbal communication. In short, the interviews are about personal truth, not about absolute truth.

An interview can be conducted in face to face settings or via the telephone. In both cases the interview is recorded resulting in an audio file. The general question within the interview focuses on the major lessons the interviewee has learned within the project, supplemented by experiences of the interviewee on some of the issues raised in previous interviews. The interviewer should prompt for additional details to get a richer picture, by asking several interviewees about the same major issues we get multiple views on the same issues.

The interview is recorded as a spoken document. However, while it is easy to scan a text to get an overview over the content, spoken documents do not support scanning (Barron, 2004). Therefore, we ask

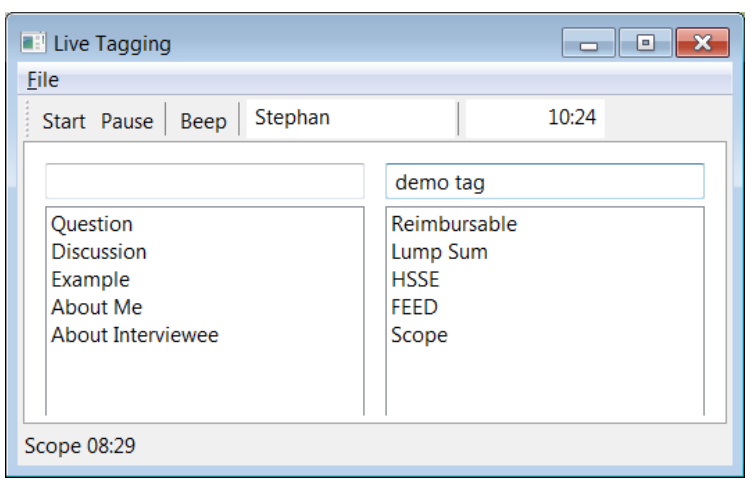

Figure 1: Live tagging

the interviewer (or an additional observer) to tag the interview while it takes place (see Figure 1); this technique is similar to live tagging (Kelkar et al., 2010). A tag consists of a label and a time index and provides a rough indication of the topic or interaction type (e.g. asking a question) within the interview at a given time. In order to match the recording time and the internal clock of the tag application we use a load sound (beep) when we start the tagging application (this is similar to the use of a clapperboard in motion picture production to synchronize images and sound).

\subsection{Processing}

Even though eliciting softer types of knowledge through interviews aims to reduce the time and effort a project manager spends on the process and provides motivation to actually tell the stories, the one-by-one interviews also require a story editor to analyze and process the interviews. Consider the following examples:

- The interviewees address multiple issues in one interview which have to be separated and distributed to different recipients.

- To highlight a particular connection within a course it can be enough to use a couple of small stories serving as examples.

- For a more extensive documentation of one issue within the project the views of several interviewees have to be combined.

These examples show that there is a gap between the elicitation of the experiences and the utilization of these captured experiences-we can not just use the raw interviews. Even though the exact purpose of using parts of the interviews differ, there are some commonalities when looking at the underlying activities: the story editor identifies and labels interesting parts (or segments) of the interviews, links different parts of the interviews exports results as an audio file. 


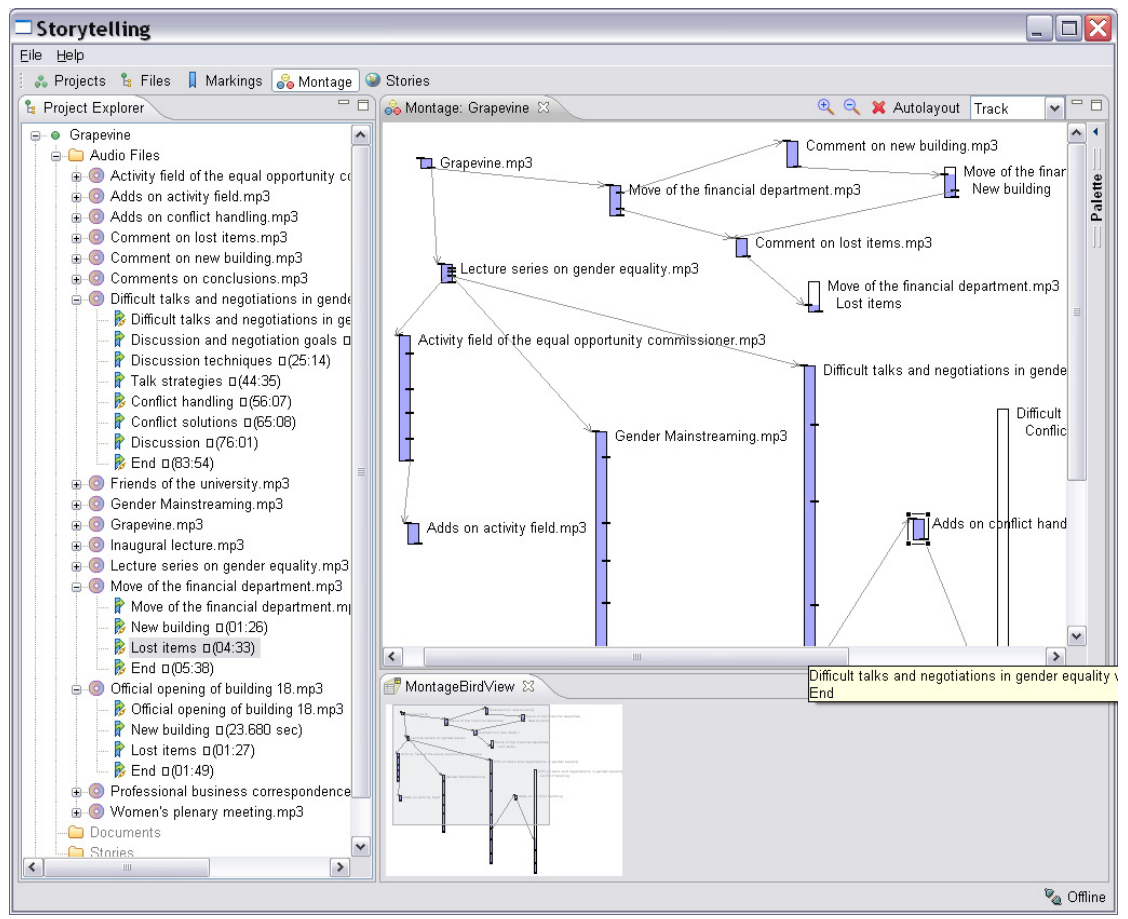

Figure 2: CASTing (Lukosch et al., 2008)

The processing phase supports these activities through three steps:

1. Segmentation of the interviews

2. Linking of the segments

3. Merging different segments together

To assist story editors in the execution of this process we used the CASTing information system (Lukosch et al., 2008). CASTing offers functionality to collaboratively store, mark, tag, link, search, publish and reuse the audio material. The identification of interesting parts takes place during the segmentation step. Story editors can segment the audio recordings by setting marks; each mark is defined by a label and a exact time position in the interview. In Figure 2 on the left side you can see a list of audio files together with their marks. Two marks within the same interview define start and end of a segment. The marks in an audio recording can be used to define links between interviews by serving as start or end point for a link. Based on the marks that are associated with each audio recording it is possible to link the original interviews without modifying them. The links between the different audio recordings form a directed graph (see Figure 2, right side). The nodes in the graph represent the parts of the interviews, the directed edges in the graph represent the links between these parts. Each node is assigned to one audio recording. By using directed graphs we allow story editors to explore several alternatives before committing to one of them.
Within the directed graph story editors can select a single thread and export this threat as a single audio file.

The three steps of the processing stage may be executed in any non-sequential order. It is possible to skip steps or to return to steps in the process. Thereby, we support a free development of the story. When, e.g. linking audio recordings the need for an additional example can become obvious. This example can be identified and then directly be linked.

\section{EXPERIENCES}

In order to test our approach we have employed it in a major oil and gas company. In the following we describe our experiences in capturing and processing personal experiences of knowledge people involved in the management and supervision of two major projects within that company and derive some insights into what went well and which points need improvement. Furthermore we report on using some of the elicited stories as educational material in a formal training environment.

\subsection{Capturing of personal experiences}

We have carried out the capturing phase within two projects, one in Russia and one on the Arabian Peninsula. Both projects were already running for sev- 
eral years and near completion at the time of the interviews. Within these projects it was important to gather experiences in time (that is, before people move onto the next project or leave the organization). The personal experiences were captured through semi-structured interviews focusing on the lessons learned within these projects. The lead question in most interviews was

What are the three major lessons you learned within this project?

The interviews were conducted by individuals or in teams; for each of the two projects there was one lead interviewer. Even though this lead interviewer had prepared a list of topics he wanted to address most of these topics were already addressed by answering this simple question. If necessary, the interviewer would use this list of topics to ask further questions. All in all, it was remarkably easy to elicit the experiences of the project managers through interviews.

Besides, there are other advantages that deserve mentioning. The time an individual project manager had to spent on the process lay between 40 minutes and 2:30 hours (see Table 1), which is quite low compared to the amount of information shared in that time. For instance, the transcript of the longest interview contained over 20,000 words. Therefore, with the chosen approach we reach our goal to reduce the time a project manager has to spent on the process. We have to point out though, that the time needed might depend on the interviewer as well. In Russia and on the Arabian Peninsula two different interviewers were leading the interview. As shown in Table 1 there is a difference of 20 minutes between the mean lengths of the interviews and a considerable difference can also be noticed when looking at the minimum (40 min versus $69 \mathrm{~min}$ ) and maximum lengths (95 min versus $148 \mathrm{~min}$ ) of the interviews. Differences between interviewers include the number of questions asked in the interview and the number of verbal supporting cues (like "hm").

However, two leading interviewers do not provide us with sufficient data. Therefore these observations have to be substantiated through further research.

Furthermore, our approach allows us to elicit stories (and not just facts) in an interactive way thereby offering an easy way to share experiences. For example, one project manager addressed the learning aspects of stories as well as motivational aspects for participating in our research:

I was keen to participate because I very strongly believe in storytelling. Because stories they stick and if you can tell a story then people will remember the story and if in that story are some points that he can pick up,
Table 1: Interviews

\begin{tabular}{|l|l|l|}
\hline Location & Russia & $\begin{array}{l}\text { Arabian } \\
\text { Peninsula }\end{array}$ \\
\hline $\begin{array}{l}\text { Number of Inter- } \\
\text { viewees }\end{array}$ & 13 & 9 \\
\hline $\begin{array}{l}\text { Length of inter- } \\
\text { views (Range) }\end{array}$ & $\begin{array}{l}40 \mathrm{~min} \text { to } \\
95 \mathrm{~min}\end{array}$ & $\begin{array}{l}69 \mathrm{~min} \text { to } \\
148 \mathrm{~min}\end{array}$ \\
\hline $\begin{array}{l}\text { Length of inter- } \\
\text { views (Mean) }\end{array}$ & $69 \mathrm{~min}$ & $89 \mathrm{~min}$ \\
\hline $\begin{array}{l}\text { Total interview } \\
\text { time }\end{array}$ & $\approx 15$ hours & $\begin{array}{l}\approx \text { 13.5 } \\
\text { hours }\end{array}$ \\
\hline
\end{tabular}

which are applicable for their own knowing. [...] The other element which is important is that major project teams like mine, they are isolated. They go on a journey and [...] in my case it will be 8 years. [...] And the learning happens during those 8 years and yes at a certain phase you write them down and - it should be pulled. That's why the storytelling that you invited me to is pulling the information and not waiting till the project team writes it down.

Here the project manager points out that capturing experiences through interviews has the additional advantage of pulling the experiences instead of just waiting for them to be delivered.

Finally, during the interview the interviewees felt free to address any issue they deemed important. Major issues were addressed by several interviewees resulting in a rich picture. The interviewees addressed questions and opinions that are not part of the lessons learned approach (within that company), e.g. they highlighted drawbacks of solutions, they brought up untried ideas, addressed unresolved problems and highlighted connecting challenges.

We also identified additional challenges and limitations: First, even though the interviewees shared their experiences freely, they also asked the interviewers to limit access to some sensitive issues in their stories. Second, ethical issues are raised when the interviewees share negative experiences they had with employees of the company. Third, capturing experiences is not suitable for recreating past events, particularly when these events had a huge impact on a project.

\subsection{Processing}

In order to evaluate our processing step, stories containing personal experiences and beliefs regarding contracting were selected and reconstructed with the help of CASTing. Within the processing stage the story editors were able to identify lessons learned, 
heuristics, contextual information, how to do something and stories about particular incidents. These stories within stories were used as illustrations by the interviewees and proved useful as examples for the educational material.

Using CASTing the story editors marked small parts of the interviews and rearranged these parts into two narratives. These narratives were presented in a course for novice project managers. The story editors identified these parts with the help of the interviewers. Once the story editors identified the parts they wanted to use, the CASTing support allowed them to extract these parts, tag them and create a narrative out of it. However, the identification itself proved to be quite time consuming and cumbersome. This experience shows the need for suitable tool support: through intense discussion with the story editors it became evident that, as a first step, the accessibility of spoken documents needs to be improved.

\subsection{Evaluation in a training program for project managers}

The stories were employed in a formal training environment within the oil and gas company to test the acceptance and applicability of stories to convey knowledge and to contribute to continuing professional development.

\subsubsection{Educational Material}

In order to evaluate the stories with regard to context as well as technical quality we designed an intervention utilizing selected story parts relating to contracting issues (specifically remuneration schemes). The stories were reconstructed from interviews with two senior project managers each responsible for one subproject. For each project manager one file (3 min and 1 min length respectively) was created, containing experiences within their own sub-project as well as their personal views on the other sub-project, together with specific examples underlining their position. When selecting the stories we paid special attention to other topics relevant in project management (e.g. safety, scope change). In addition to the stories themselves we assembled contextual information on the main project and on the project managers; this information was presented separately from the stories.

\subsubsection{Setting and Participants}

The reconstructed stories were employed in two continuing education courses for professionals within the organization. The courses addresses beginners in project management and took place in The Netherlands and in Brunei (see Table 2 for details about the participants).

Table 2: Participants

\begin{tabular}{|l|r|r|}
\hline Location & The Netherlands & Brunei \\
\hline $\begin{array}{l}\text { Number of Partic- } \\
\text { ipants }\end{array}$ & 23 & 24 \\
\hline $\begin{array}{l}\text { Participants with } \\
\text { prior knowledge } \\
\text { about contracting }\end{array}$ & 13 & 15 \\
\hline Age (Range) & & \\
\hline Age (Mean) & $27-49$ & $24-52$ \\
\hline
\end{tabular}

\subsubsection{Procedure}

The overall intervention was divided into three parts and took about 35 minutes. In the first part a course facilitator gave a short introduction on the project. The first audio file was introduced with some background information on the project manager and the file was played back. The same procedure was followed for the second audio file. Altogether, the first part took 10 minutes. In the second part the course participants discussed the advantages and disadvantages of various remuneration schemes in small groups and captured their results on a flip chart. This group discussion lasted about 15 minutes. In the final part a plenary discussion was used to debrief the course participants.

After the intervention we collected feedback from the participants through a questionnaire containing both qualitative and quantitative questions (using a 7 point Lickert scale). Here we were mainly interested in the following two questions:

1. Do the participants perceive the use of frozen stories about real projects as interesting and relevant?

2. Do frozen stories remind participants of their own first-hand experiences or of stories they have heard from others?

We also asked the participants what they found good and how we could improve the use of stories in an educational setting.

\subsubsection{Results}

In both locations, we explored how the stories were perceived as part of the course (see Table 3 ). The results show that while $71.1 \%$ of the participants support the use of stories in future courses, $60.0 \%$ of the participants perceived the stories as interesting and $91.3 \%$ perceived them as relevant for the course, the implementation of using stories in an educational 
settings needs improvement with regard to the audio quality and the provided contextual information. Only $46.8 \%$ of the participants considered the context to be sufficient, and $71.7 \%$ found the audio quality insufficient. We want to point out the discrepancy between the perception of the audio quality in Brunei and The Netherlands: while $91.7 \%$ of the participants in Brunei found the audio quality insufficient, only $50.0 \%$ of the participants in The Netherlands found the quality insufficient. This discrepancy might be explained by the proficiency in English in both courses. In Brunei, the qualitative results showed some support for using audio or video aids (e.g. subtitles) which supports this assumption. In addition, several participants suggested replacing the audio material with video.

Table 3: Applicability of stories (The Netherlands and Brunei)

\begin{tabular}{|l|l|l|l|}
\hline Item & Agree & Neutral & Disagree \\
\hline $\begin{array}{l}\text { Perceived as rele- } \\
\text { vant for the course }\end{array}$ & 91.3 & 2.2 & 6.5 \\
\hline $\begin{array}{l}\text { Perceived as inter- } \\
\text { esting }\end{array}$ & 60.9 & 28.3 & 10.9 \\
\hline $\begin{array}{l}\text { More stories in fu- } \\
\text { ture courses }\end{array}$ & 71.1 & 22.2 & 6.7 \\
\hline $\begin{array}{l}\text { Sufficient contex- } \\
\text { tual information }\end{array}$ & 46.8 & 27.7 & 25.5 \\
\hline $\begin{array}{l}\text { Sufficient audio } \\
\text { quality }\end{array}$ & 10.9 & 17.4 & 71.7 \\
\hline
\end{tabular}

In Brunei we added some questions, mainly to follow up on issues raised during the course in The Netherlands. We found that $81.8 \%$ of the participants found the stories relevant for their peers, thereby substantiating the relevance of the stories for beginners in project management.

Furthermore, we explored the issue of the contextual information by splitting it up into information relating to the narrators of the stories and information relating to the project itself. While $45.8 \%$ of the participants found the contextual information about the persons sufficient, only $34.8 \%$ found the contextual information from the project sufficient. In order to improve the applicability of stories within educational settings we therefore have to improve the contextual information in both areas.

Some participants in The Netherlands observed that they were reminded of their own experiences. The results from Brunei show however, that $68 \%$ of the participants are reminded of stories they had heard before. Only $35.3 \%$ are reminded of their own experiences. Even though, $83.3 \%$ of the partipants agreed that their own experiences or that of their peers were shared during the group discussion; and only $29.2 \%$ found it difficult to share their own experiences. All in all, this suggests that while experiences were shared in the group discussion, sharing of own experiences was somewhat limited. This conclusion is supported through qualitative results. For instance, one participant stated

A good discussion amongst the team but limited to what the team knows and what they have experienced before. Discussion with a wider group added more insight but still very limited as not many of the participants have encountered contracting strategy.

Table 4: Results Brunei

\begin{tabular}{|l|l|l|l|}
\hline Item & Agree & Neutral & Disagree \\
\hline $\begin{array}{l}\text { The stories are rele- } \\
\text { vant for peers }\end{array}$ & 81.8 & 18.2 & 0 \\
\hline $\begin{array}{l}\text { Reminded of own } \\
\text { experience }\end{array}$ & 35.3 & 52.9 & 11.8 \\
\hline $\begin{array}{l}\text { Reminded of stories } \\
\text { heard before }\end{array}$ & 68.2 & 22.7 & 9.1 \\
\hline $\begin{array}{l}\text { During discussion } \\
\text { own experiences } \\
\text { and that peers } \\
\text { were shared }\end{array}$ & 83.3 & 8.3 & 8.3 \\
\hline $\begin{array}{l}\text { Difficult to share } \\
\text { experiences during } \\
\text { discussion }\end{array}$ & 29.2 & 12.5 & 54.2 \\
\hline $\begin{array}{l}\text { Sufficient back- } \\
\text { ground information } \\
\text { on project manager }\end{array}$ & 45.8 & 29.2 & 25.0 \\
\hline $\begin{array}{l}\text { Sufficient back- } \\
\text { ground information } \\
\text { on project }\end{array}$ & 34.8 & 26.1 & 39.1 \\
\hline
\end{tabular}

The qualitative results give some additional insights into effects of the intervention. First, the participants appreciate the real life experiences. For example, one participant stated

We get to understand how method succeed or failed in real life situation.

Second, the participants gained insights into the content. One participant stated:

It's an eye-opener in some ways that reimbursable $^{1}$ are good in some situations.

With regard to the two questions posed above, we can conclude that the course participants perceived the use of frozen stories as interesting and relevant, despite the insufficient audio quality. Furthermore,

\footnotetext{
${ }^{1}$ Reimbursable is one of the remuneration schemes.
} 
they are often reminded of stories they have heard from others, but they are rarely reminded of their own first-hand experience.

\section{CONCLUSIONS AND FUTURE WORK}

In this paper, we presented an approach to support the elicitation and processing of stories and experiences of project managers, thereby allowing organizations to share rich accounts of these experiences across time and space. We employed our approach in two projects of a major oil and gas company. Our approach consists of two stages, the capturing of experiences through semi-structured interviews and the processing of these interviews. The capturing stage allows project managers to freely communicate their stories and experiences, while leaving room for the elaboration of untested ideas, unresolved challenges and drawbacks of tried solutions. The processing stage builds on a process designed for collaborative storytelling and features the segmentation of the interviews, linking of various segments and the merging of linked segments.

We extracted two stories about contracting and employed these in a formal training environment to test the acceptance and applicability of stories to convey knowledge and to contribute to continuing professional development.

Even though our experiences with the approach show promising results, we want to point out some limitations and opportunities for future research. First, it was easy to capture the experiences of project managers. However, as the target group were project managers, we might find it more difficult to capture the experiences of other knowledge people like scientists or engineers.

As discussed in section 4.2, the segmentation of the interviews in the processing stage is still time consuming. Therefore, as a first step we want to improve the accessibility of the spoken stories.

Furthermore, the qualitative results from the educational setting showed that the exchange of own experiences was limited during the group discussion. Apprentice project managers do not have enough own experiences to draw upon during discussion. In future research, we intend to investigate approaches to provide novices and apprentices with a wider base for discussion, e.g. by instructing participants of a course to ask colleagues about their experiences in advance of the course.

Finally, within the domain of knowledge management the use of captured knowledge within an organi- zation often poses a challenge. In our future work, we will therefore use frozen stories not just in formal educational settings but also integrate them into the daily work practices of project managers. We are currently exploring possiblities to utilize frozen stories within decision making and problem solving situations.

\section{REFERENCES}

Argyris, C. (1980). Some limitations of the case method: Experiences in a management development program. The Academy of Management Review, 5(2):291 - 298.

Barron, A. E. (2004). Auditory instruction. In Jonassen, D. H., editor, Handbook of research for educational communications and technology (clone) - a project of the Association for Educational Communications and Technology. Lawrence Erlenbaum Associates, Mahwah, NJ.

Brown, J. S. and Duguid, P. (2000). Balancing act: Capturing knowledge without killing it. Harvard Business Review, 78(3):73-80.

Bruner, J. (1991). The narrative construction of reality. Critical Inquiry, 18(1):1-21.

Cooke-Davies, T. (2002). The real success factors on projects. International Journal of Project Management, 20(3):185 - 190.

Gandelman, R. and Santoro, F. (2010a). A collaborative approach to compose training content. In Systems Man and Cybernetics (SMC), 2010 IEEE International Conference on, pages 2880-2885.

Gandelman, R. T. and Santoro, F. M. (2010b). Designing training content through group storytelling. In Computer Supported Cooperative Work in Design (CSCWD), 2010 14th International Conference on, pages 689-694.

Grant, K. A. and Qureshi, U. (2006). Knowledge management systems - why so many failures? In Innovations in Information Technology Conference 2006 Dubai, $U$ Arab Emirates, pages 87-91, Los Alamitos, CA. IEEE Press. Innovations in Infor... Innovations in Information Technology Conference 2006, Dubai, U ARAB EMIRATES, NOV 19-21, 2006.

Hansen, M. T., Nohria, N., and Tierney, T. (1999). What's your strategy for managing knowledge? Harvard Business Review, 77(2):106-116.

Jashapara, A. (2004). Knowledge management - an integrated approach. Prentice Hall, Harlow.

Joung, W., Hesketh, B., and Neal, A. (2006). Using' war stories' to train for adaptive performance: Is it better to learn from error or success? Applied Psychology, 55(2):282.

Kelkar, S., John, A., and Duncan Seligmann, D. (2010). Some observations on the 'live' collaborative tagging of audio conferences in the enterprise. In $\mathrm{CHI}$ ' 10 : Proceedings of the 28th international conference on Human factors in computing systems, pages 995-998, New York, NY, USA. ACM. 
Lukosch, S., Klebl, M., and Buttler, T. (2008). Facilitating audio-based collaborative storytelling for informal knowledge management. In Briggs, R. O., Antunes, P., and Vreede, G.-J. d., editors, Proceedings of the 14th Collaboration Researchers' International Workshop on Groupware (CRIWG 2008), pages 289-304, Berlin, Heidelberg. Springer.

Lukosch, S., Klebl, M., and Buttler, T. (in press). Utilizing verbally told stories for informal knowledge management. Group Decision and Negotiation.

McDermott, R. (1999). Why information technology inspired but cannot deliver knowledge management. California Management Review, 41(4):103-117.

McDrury, J. and Alterio, M. (2003). Learning through storytelling in higher education - using reflection und experience to improve learning. Kogan Page, London [u.a.].

Neuweg, G. H. (2006). Das Schweigen der Könner - Strukturen und Grenzen des Erfahrungswissens. Trauner Verlag, Linz.

Newell, S., Bresnen, M., Edelman, L., Scarbrough, H., and Swan, J. (2006). Sharing knowledge across projects. Management Learning, 37(2):167-185.

Newell, S., Robertson, M., Scarbrough, H., and Swan, J. (2002). Managing knowledge work. Palgrave Basingstoke, Hampshire.

Nonaka, I. and Takeuchi, H. (1995). The knowledge creating company - how Japanese companies create the dynamics of innovation. Oxford Univ. Press, New York, NY, USA.

Ochs, E. and Capps, L. (2001). Living narrative: Creating lives in everyday storytelling. Harvard Univ Pr.

Orr, J. E. (1996). Talking about machines - an ethnography of a modern job. ILR Press, Ithaca, NY.

Pelt, T. v. (2008). Building bridges between projects. Master's thesis, TU Delft.

Perret, R., Borges, M. R. S., and Santoro, F. M. (2004). Applying group storytelling in knowledge management. In Vreede, G.-J. d., Guerrero, L. A., and Ravents, G. M., editors, CRIWG, volume 3198, pages 34-41, Berlin, Heidelberg. Springer.

Rickert, A. and Schnalzer, K. (2005). Mediengestütztes Lernne mit betrieblichen Geschichten. In Reinmann, G. E., editor, Erfahrungswissen erzählbar machen narrative Ansätze für Wirtschaft und Schule, pages 19-35. Pabst Science Publ, Lengerich.

Sage, A. P. and Armstrong, J. E. (2000). Introduction to systems engineering. John Wiley \& Sons, Chichester.

Schank, R. C., Fano, A., Bell, B., and Jona, M. (1994). The design of goal-based scenarios. Journal of the Learning Sciences, 3(4):305-345.

Simon, H. A. (1977). The new science of management decision. Prentice-Hall, Englewood Cliffs; London.

Spender, J.-C. (1996). Making knowledge the basis of a dynamic theory of the firm. Strategic Management Journal, 17(SUPPL. WINTER):45-62.
Spender, J.-C. (1998). Pluralist epistemology and the knowledge-based theory of the firm. Organization, 5(2):233-256.

Stauffer, D. (1999). Why people hoard knowledge. Across the board, 36(8):16-21.

Totzke, R. (2005). Erinnern - Erzählen - Wissen - Was haben (Erfahrungs-)Geschichten mit echtem Wissen zu tun? In Reinmann, G. E., editor, Erfahrungswissen erzählbar machen - narrative Ansätze für Wirtschaft und Schule, pages 19-35. Pabst Science Publ, Lengerich.

Valle, C., Raybourn, E. M., Prinz, W., and Borges, M. R. S. (2003). Group storytelling to support tacit knowledge externalization. In Proceedings of the 10th International Conference on Human-Computer Interaction, pages 1218-1222, Crete, Greece. 